\title{
Cristianismo y Revolución. Los orígenes intelectuales de la guerrilla en la Argentina
}

\author{
Gustavo Morello
}

Editorial de la Universidad Católica de Córdoba (EDUCC), Córdoba, 2003, 378 págs.

\section{Guillermo Barón Del Pópolo*}

Recibido: 15.04.2010

Aceptado: 16.06.2010

$* * *$

El libro que reseñaremos a continuación fue publicado en el año 2003 como primer número de la colección Thesys de la Editorial de la Universidad Católica de Córdoba, Argentina. Una pequeña nota en la contrasolapa nos informa que estamos, con esta colección, delante de “...una selección de obras de múltiples disciplinas, elaboradas a partir de los trabajos de Tesis de posgrado, presentadas y defendidas públicamente por docentes e investigadores de la U.C. de Córdoba., en distintas instituciones de educación superior de nuestro país y el extranjero”.

En este caso en particular se trata de una reelaboración de la Tesis presentada por el padre Gustavo Morello para optar al título de Magíster en Ciencias Sociales por la Universidad Nacional de Córdoba.

Estos datos, necesarios para la elaboración de cualquier tipo de reseña, se nos presentan como especialmente importantes en este caso. Cristianismo y Revolución. Los orígenes intelectuales de la guerrilla en la Argentina., no está escrito desde cualquier lugar, y no simplemente desde el cristianismo, sino desde el de un investigador plenamente inserto en la institucionalidad católica. Incluso la publicación del trabajo está vehiculizada por esta misma institucionalidad.

El objeto estudiado en la Tesis de Morello es la revista Cristianismo y Revolución, publicación clave en el análisis de la historia política de los años '60 y '70. Dicha publicación tuvo una tirada de 30 números entre 1966 y 1971 y fue referencial para los cristianos revolucionarios en parti-

*Universidad Nacional de Cuyo, Mendoza, Argentina. Email: guillermobaron@yahoo.com 
cular y para todo el campo de la militancia revolucionaria en general.

El libro está conformado por cuatro capítulos, un prólogo, a cargo de Horacio Crespo, una introducción, unas reflexiones finales y dos anexos. Los títulos de dichos capítulos son: I.- El Cambio de Paradigmas en la Iglesia del Siglo XX; II.- Los Años Sesenta; III.- Cristianismo y Revolución y IV.- Cristianismo y Revolución, una lectura.

En su intento de "aproximarse al hecho social" la obra asume el “paradigma hermenéutico” (pág. 41), partiendo del "supuesto de la racionalidad del actor social: los protagonistas de un hecho político pueden dar razón de lo que hacen, tienen argumentos que justifican sus comportamientos. El grupo de Cristianismo y Revolución se identifica como cristiano y revolucionario; intentarán entonces explicar su compromiso revolucionario desde su fe cristiana, católica en particular. Por eso buscaremos los puntos en que la teología cristiana condiciona el accionar político del grupo” (pág. 41).

Es dentro de esta lógica que puede entenderse la función de los capítulos del libro. Los dos primeros (I.- El Cambio de Paradigmas en la Iglesia del Siglo XX. y II.- Los Años Sesenta.) son el marco contextual desde él cual se plantea la lectura particular que el padre Morello realiza del corpus de la revista. Los dos últimos (III.-Cristianismo y Revolución. y IV.-Cristianismo y Revolución, una lectura.) son de aplicación, en ellos se intenta entender el significado del discurso cruzándolo por las variables definidas en el contexto.

La tesis central que la obra defiende es que "la participación de actores cristianos en los movimientos revolucionarios argentinos entre 1966 y 1971, fue fruto de una radicalización del cristianismo. Fue violencia cristiana, en diálogo con la Izquierda, inmersa en la violencia, pero fundamentalmente arraigada en la conciencia cristiana de dichos actores.” (pág. 42)

\section{Problemas de método}

Morello nos promete un interesante análisis de $C$ y $R$ por el cual soportamos pacientemente el largo recorrido de los dos capítulos iniciales, una abultadísima descripción histórica del Concilio Vaticano II y otra del “espíritu de época” de los años sesenta. El primer capitulo es justificado por el padre Morello en el sentido de que para él es en la enseñanza social de la Iglesia oficial que los cristianos encuentran su aval para la acción revolucionaria (ibídem), posición con la cual se nos permitirá polemizar más adelante.

Después de estos dos capítulos nos sorprende lo escueto del tercero. En este se da cuenta sucintamente del perfil y los objetivos de la revista, las características del corpus, las diferentes secciones y el equipo editorial. Muchos de los datos proporcionados aquí, como las secciones y el análisis 
del equipo, parecen estar consignados por pura forma ya que no se los hace jugar en la "lectura” efectuada en el capítulo IV.

Luego se realiza una breve reseña biográfica del director de la revista, Juan García Elorrio, plagada de datos intrascendentes (como el de su desempeño en la escuela primaria, “Decayó un poco en el cuarto año” consigna fielmente Morello) y escasa en información esencial.

Para terminar; se reproducen en forma resumida los 23 editoriales que García Elorrio redactó para $C y R$. Los editoriales de los números que aparecieron luego de la muerte de este no están consignados.

El capítulo IV nos hace preguntarnos de qué se trata realmente este “paradigma hermenéutico” en el que se para Morello a la hora de analizar la revista. El tipo de lectura del material “en conjunto” (pág. 42) que propone el jesuita, "sin prestar tanta atención a las firmas” no nos parece el más acertado. Tampoco parece válida la excusa de recrear una "lectura militante” ya que "los lectores eran de Cristianismo y Revolución y no tanto de uno u otro columnista”.

A la hora de analizar un discurso polifónico, como el de una revista, y a la de analizar un corpus distribuido en cinco años de historia (más teniendo en cuenta lo particularmente dinámico de este periodo histórico) no podemos proceder de la misma manera que al analizar, por ejemplo, un libro.

"Se podría objetar que las notas de la revista que llevan firma no pueden ser trabajadas en el mismo conjunto que las notas de la redacción de la revista” (pág. 315) nos advierte Morello, y nos preguntamos porqué no hizo caso de su propia advertencia. Ante lo cual responde que "los editoriales de Juan García Elorrio marcan una línea, trazan un perfil hacia el cual se orienta toda la publicación. Más allá de las diferentes firmas, de los diferentes temas tratados, este es el criterio según el cual se selecciona el material (a publicar en la revista)” (ibídem).

Es claro que cuando decimos que estamos ante un discurso polifónico no queremos decir “desarticulado”, pero esa misma articulación, ese juego entre los distintos redactores, entre las diferentes columnas y tipos de columnas y secciones, algunas con registros más “teóricos” otras más panfletarias y cruzadas por la urgencia militante, como los editoriales, no está registrada en el estudio de Morello. Las líneas editoriales, supuesta clave articuladora en la lectura de todo el corpus, están meramente reproducidas sin ningún tipo de análisis, ni siquiera uno que pudiera llegar a cruzarlas con la coyuntura histórica del momento en el que aparecieron.

Aquí el padre Morello vuelve a señalarnos el camino, para no seguirlo él mismo: A pesar de que según él "los matices que notamos en el pensamiento de Cristianismo y Revolución, tienen que ver más con una radicalización de sus posturas a lo largo del tiempo, que con matices ideo- 
lógicos” (pág. 316) no hay en su lectura del corpus ningún tipo de ordenamiento en este sentido, ninguna consideración de la variable temporal e histórica. Sintomático de esto es el desorden de las citas que se toman para referenciarla. No sólo las citas son de artículos de diferente orden y registro (es importante recordar que la revista publicaba incluso fragmentos de libros, entrevistas extraídas de otros ámbitos, documentos de organizaciones a las que la unía una suerte de "ecumenismo revolucionario" pero con las cuáles no significaba que se coincidiera totalmente ${ }^{1}$ ), sino que es común ver citas de artículos de los primeros números junto a citas de los últimos.

La "lectura" de Morello se estructura en torno a cinco ejes (1. El diagnóstico de la situación; 2. La revolución socialista; 3. Amigos y enemigos de la revolución; 4. La construcción de la Patria Socialista y 5. La misión de la Iglesia.), cada uno con sus ejes subordinados. En ningún momento se plantea la pertinencia de estos ejes para el análisis. Es cierto que podemos en cierta manera inferirlos de los marcos contextual-interpretativos que Morello propone, pero no hay ningún tipo de justificación en cuanto a porqué elegir esos conceptos eje y no otros, que a nuestro entender podrían haber aportado herramientas interpretativas que fueran más allá de las coordenadas obvias en las que se enmarca la producción de la revista.

\section{Un supuesto peligroso: el antiliberalismo}

La tesis no explícita que cruza todo el libro es la del rechazo común por parte de Iglesia e izquierda hacia la modernidad liberal. Según esta tesis "fue una alianza estratégica contra el capitalismo, positivista y liberal, lo que acercó a la Iglesia con el marxismo” (pág 298). Para Morello, “el enemigo siempre fue el liberalismo” (pág. 297). Según él "podemos explicar el enfrentamiento de la Iglesia con el marxismo 'leyendo' lo que el comunismo tuvo de liberal: su ateísmo, y la censura a lo religioso en la vida pública”.

Lo que el padre Morello parece no ver, y que a nuestro entender es lo esencial en este tema, es la diferencia en el carácter de las críticas efectuadas por Iglesia y marxismo.

Si se nos permite el uso de categorías taxativas, pero en este caso muy útiles, como son las de "izquierda” y "derecha” podremos entender esta diferencia.

La crítica tradicional de la Iglesia al liberalismo es "por derecha", reaccionaria la mayoría de las veces (como Morello reconoce); mientras

\footnotetext{
${ }^{1}$ La revista solicita Definiciones a diferentes personas, no con el objetivo de adoptarlas como propias, pero si para presentarlas como un "valioso material de doctrina y formación de una conciencia revolucionaria.” (pág. 143).
} 
que el marxismo critica al liberalismo superándolo y conteniéndolo, es una crítica "por izquierda". Arriesgar que estas críticas sean coincidentes, de algún modo, es adherir a aquel dudoso principio por el cual en política "los extremos se tocan", digno de los oscuros pensamientos sofistas del Leo Naphta de Thomas Mann.

Es más, tampoco queda muy en claro que es lo que entiende Morello por "liberalismo". Es para él algo negativo, sin duda, pero realmente no se entiende qué es. A veces pareciera establecerlo sin más como un equivalente de "capitalismo", otras amontona conceptos como "modernidad", "positivismo", "iluminismo", en un intento vano de definir "lo malo" por yuxtaposición.

Afinar este concepto también ayudaría a entender las particularidades de la crítica de marxismo e Iglesia. Si bien el marxismo es esencialmente anticapitalista, no ha sido, ni debe necesariamente ser, antiliberal. Es más, incorpora en su crítica los mejores elementos del radicalismo burgués. Por otro lado, aunque la Iglesia aún en pleno siglo XXI y retrocediendo en lo avanzado en el siglo XX sigue posicionándose en un campo cerradamente antiliberal, no podemos decir que necesariamente se sienta muy incómoda con el capitalismo.

Incluso el mismo Morello argumenta en contra de su propio supuesto. A lo largo de todo su relato acerca del reformismo católico de mediados del siglo XX, nos habla de una "reconciliación de la Iglesia con el mundo, con la historia". Esta reconciliación con el mundo lo es particularmente con los países del "occidente liberal” euroamericano. Aún el pensamiento social católico fue pensado como una reforma que evitara la revolución inminente, a la manera del reformismo capitalista del mismo periodo (págs. 84 - 85), y lograra cortar el peligro comunista de raíz.

Sin embargo, para Morello, es este pensamiento católico posconciliar el que "avala” a los revolucionarios, y no el preconciliar, este sí esencialmente antiliberal.

En este sentido es muy importante marcar una diferencia clara entre "reformismo conciliar” y "cristianismo revolucionario". Por más que el segundo recurrió repetidamente al primero en busca de un "aval”, de una legitimación frente al "pueblo cristiano", y de que de hecho el primero también sirvió de disparador de procesos cristianos de radicalización, la diferencia es esencial: mientras el reformismo católico busca una reconciliación con el presente, el cristianismo revolucionario tiene un compromiso con el futuro.

A nuestro juicio es esto, y no la crítica al "liberalismo" lo que explica la alianza estratégica entre marxismo y cristianismo. El compromiso con el futuro. Y el humanismo.

La teología de la liberación teóricamente y el cristianismo revolu- 
cionario en la praxis, efectúan en el pensamiento religioso una inversión paralela a la que el marxismo realiza con la filosofía. Ponen con los pies en la tierra lo que estaba de cabeza. Vuelven al hombre concreto, necesitante y deseante, del primer cristianismo y de la tradición semítica. Una inversión paralela que incluso es una y la misma, ya que la filosofía idealista es el resultado directo del "occidente cristiano"2.

Es en este sentido que podemos entender al cristianismo revolucionario, está muchísimo más allá que el pensamiento del tradicionalismo católico porque incluso ha superado, dialécticamente, al reformismo católico. Por ello podemos entender la posición adecuadamente resaltada por Morello de la búsqueda del lugar de los cristianos en una "revolución laica” en contra de una Cristiandad de Izquierda (si tal cosa fuera posible siquiera conceptualmente). El compromiso de los cristianos revolucionarios es, como dijimos, con el futuro, y con un futuro plenamente "moderno”. A pesar de contener elementos románticos y místicos (¿qué pensamiento revolucionario no los tiene?) el cristianismo revolucionario se apoya en la razón y el humanismo para ir en busca de la última utopía moderna, el socialismo, en contra de la irracionalidad capitalista.

\section{Iglesia Pueblo de Dios, Iglesia Institución, Cristianismo como cultura}

Otro de los conceptos que en la obra del padre Morello no encontramos satisfactoriamente definidos es el de Iglesia. En la Introducción, Morello nos habla de las diferentes definiciones de Iglesia. Por un lado, el concepto tradicional, de la Iglesia como la institución jerárquicamente ordenada, del clero. Por otro lado el concepto de Iglesia como "el Pueblo de Dios peregrino en la Tierra”. Luego nos habla del cristianismo, como parte del núcleo ético-mítico del ser americano.

Hasta aquí las definiciones son claras, el problema es que a lo largo de la obra no termina de dejarse nunca bien en claro en cuál de las acepciones se está usando, ni si se está usando en la acepción correcta.

Por ejemplo en el caso recién citado de "la alianza estratégica entre Iglesia y marxismo frente al liberalismo" no queda muy en claro quienes son realmente los sujetos de esa alianza. Si se estuviera refiriendo, por ejemplo, a la síntesis entre pensamiento cristiano y marxista realizada por

\footnotetext{
${ }^{2}$ Esta interpretación nos viene de la lectura de Enrique Dussel (particularmente "El Dualismo en la Antropología de la Cristiandad”; Editorial Guadalupe; Buenos Aires, 1974; "El Humanismo Helénico"; EUDEBA; Buenos Aires, 1974 y “El Humanismo Semita”; EUDEBA; Buenos Aires, 1969) y Franz Hinkelammert ("Las Armas Ideológicas de la Muerte”; Segunda edición revisada y ampliada; Editorial Departamento Ecuménico de Investigaciones (D.E.I.); San José y "La Fe de Abraham y el Edipo Occidental”; Editorial Departamento Ecuménico de Investigaciones (D.E.I.); San José, 2000).
} 
los militantes-redactores de Cristianismo y Revolución, hubiera sido mejor consignarlo de dicha forma, si se refiere a la unidad en la lucha entre militantes marxistas y militantes cristianos, también podría haberse consignado así. Otra posibilidad es que se esté refiriendo a sectores de la Iglesia, que se encontraban dentro de ella, en cualquiera de sus dos acepciones (como el Movimiento de Sacerdotes para el Tercer Mundo, o grupos similares constituidos por laicos pero referidos a la institucionalidad). En este caso hubiera correspondido hablar de una alianza entre "sectores" (siempre minoritarios, por cierto) de la Iglesia y militantes marxistas.

Esto también dispara toda una serie de interrogantes en cuanto a la relación directa del grupo de Cristianismo y Revolución en concreto con la institucionalidad. También en este sentido la concepción de Iglesia como la de "pueblo de Dios peregrino en la tierra" es problemática, ya que no se trata de cualquier persona que se diga cristiana, sino aquella que acepte formar parte de una comunidad en última instancia regida y organizada por el clero.

Incluso yendo más allá aún, en la Argentina el cristianismo revolucionario no se circunscribió solamente al mundo católico. La importancia y el aporte de los protestantes no fue menor. La influencia de figuras de la talla de Mauricio Amílcar López, pastor metodista, primer rector de la Universidad Nacional de San Luis, desaparecido por la dictadura genocida, y de instituciones como la del Consejo Mundial de Iglesias, pueden dar una idea de ello.

Para los cristianos revolucionarios nunca fue de importancia mayor establecer este tipo de distinciones, entre católicos y protestantes, o entre cristianos "libres". Categorías como las de "Iglesia", en cualquiera de sus dos acepciones, parecieran encontrarse limitadas a la hora de dar cuenta de este fenómeno.

\section{Conclusión}

Tenemos con el libro del padre Morello un valiosísimo aporte documental acerca de una de las publicaciones clave en el entendimiento de la política revolucionaria de los años '60 - '70. Ciertas limitaciones argumentativas del formato empleado (se reproduce casi textualmente su tesis de posgrado) complican la facilidad en la lectura del libro.

Algunos de los conceptos establecidos por Morello parecieran no provenir del estudio particular de esta revista, ni estar justificados en él. Tal vez, como dijimos antes, el formato empleado y el haber sido ideado con otros fines que los de la publicación oscurezcan el origen de estos conceptos.

Por otro lado el libro plantea innumerables series de interrogantes que exceden aquellas de las cuáles Morello se ocupa, y puede servir de disparador y antecedente para ulteriores investigaciones. 